\title{
LA IMPOSIBILIDAD DE EQUIPARAR DERECHOS SOCIALES Y LIBERALES
}

\section{THE IMPOSSIBILITY OF EQUATING SOCIAL AND LIBERAL RIGHTS}

\author{
María Beatriz Arriagada Cáceres*
}

\begin{abstract}
RESUMEN: Este artículo muestra, en primer lugar, que los dos principales argumentos que se han utilizado para distinguir a los derechos sociales de los derechos liberales se sustentan en dos diferentes conceptos de derecho subjetivo y, en segundo lugar, que las dos principales líneas argumentales por cuyo intermedio se ha procurado la equiparación de estas dos categorías de derechos fundamentales se construyen a partir de una crítica a los dos conceptos de derecho subjetivo que sirven de base a su distinción. Hecho esto, se analizan críticamente estas líneas argumentales con el propósito de mostrar que aunque ellas logran reducir la distancia que separa a los derechos sociales de los derechos liberales, no consiguen el objetivo que se proponen.
\end{abstract}

Palabras clave: Derechos sociales, Derechos liberales, Derechos fundamentales, Derechos subjetivos.

ABSTRACT: This article shows, in the first place, that the two main arguments that have been used to distinguish social rights from liberal rights are based on two different concepts of subjective right and, in second place, that the two main lines of argument through which the equalization of these two categories of fundamental rights have been procured, are constructed from a critique of the two concepts of subjective right that serve as a basis for their distinction. That done, these lines of argument have been analyzed critically in order to show that, although they are able to reduce the gap between social and liberal rights, they are not able to fulfil the intended aim.

Key words: Social rights, Liberal rights, Fundamental rights, Subjective rights.

\section{INTRODUCCIÓN}

En la literatura sobre los llamados derechos fundamentales, la distinción entre derechos liberales y derechos sociales es un auténtico lugar común ${ }^{1}$. Aunque parte importante de los trabajos que la consideran apuntan a refutarla ${ }^{2}$, la distinción tiene plena vigencia y sintetiza una cuestión relevante: mientras los derechos liberales (civiles y políticos) son indiscutiblemente reconocidos los derechos sociales son esencialmente controvertidos ${ }^{3}$.

\footnotetext{
* Profesora e investigadora de la Facultad de Derecho de la Universidad Diego Portales. Dirección postal: Av. República 105, Santiago. Correos electrónicos: maria.arriagada@udp.cl; mbeatriz.arriagada@gmail.com. Licenciado en Derecho de la Pontificia Universidad Católica de Chile. Doctora en Derecho por la Universidad de Chile.

1 La noción "derechos sociales" suele ser sustituida por otras tales como derechos socioeconómicos, derechos de igualdad, derechos de prestación, derechos de bienestar, y derechos a la justicia. Además de la noción "derechos liberales", suele contraponérsele expresiones tales como derechos civiles y políticos, derechos de libertad, derechos de abstención, derechos de defensa y derechos de no interferencia.

2 Por ejemplo, RuIz (1994) pp. 652-654.

3 VV.AA. (Tugendhat (1998) p. 238; Peces-Barba (1999b) p. 57; Martínez De Pisón (2009) pp. 89-90; Martínez Roldán (2009) p. 127) En el contexto local, ver por ejemplo, Aldunate (2008) pp. 58-59.
} 
Como la expresión derechos fundamentales no se usa en un solo sentido, sus diferentes significados suelen no ser claros y muchos de ellos están muy lejos de poder circunscribirse al ámbito de las disciplinas cuyo objeto de estudio es el derecho, para los objetivos de este trabajo, consideraré que se trata de: (i) posiciones subjetivas que, estando dirigidas a la protección de bienes considerados especialmente importantes, se fundamentan en normas jurídicas constitucionales; y (ii) posiciones en que los individuos se encuentran en relación con el Estado, excluyendo así los llamados derechos colectivos y los derechos fundamentales vistos desde la perspectiva de su eficacia horizontal.

En este contexto, los más importantes argumentos que se han utilizado para justificar la distinción entre derechos liberales y derechos sociales se sustentan en dos diferentes conceptos de derecho subjetivo.

El primero de estos argumentos consiste en que los derechos liberales (civiles y políticos) son derechos subjetivos que reflejan obligaciones estatales de abstención ${ }^{4}$ y los derechos sociales son derechos subjetivos que reflejan obligaciones estatales de prestación ${ }^{5}$. Este argumento se sustenta en el concepto kelseniano de derecho subjetivo reflejo que es coincidente con el concepto de derecho subjetivo en sentido propio hohfeldiano ${ }^{6}$. En este sentido, los derechos subjetivos no son derechos activos (a hacer algo) sino derechos pasi$\operatorname{vos}^{7}$ conferidos por normas regulativas. Un individuo tiene un derecho subjetivo frente a otro u otros, cuando ese otro u otros tienen frente al primero la obligación de realizar una acción o una abstención.

El segundo de estos argumentos se presenta en dos versiones que parten de la base de que los derechos liberales son posiciones jurídicas judicialmente exigibles frente al Estado. En la versión menos extrema, se afirma que los derechos sociales de prestación son derechos subjetivos "sobre el papel" porque no son susceptibles de garantía judicial ${ }^{8}$. En la versión

\footnotetext{
${ }^{4}$ La razón que, en principio, justifica la agrupación de los llamados derechos políticos y los llamados derechos civiles bajo una misma categoría analítica es que el contenido normativo activo que se atribuye a los primeros no modifica la relación de identidad que existe entre su contenido normativo pasivo y el contenido normativo exclusivamente pasivo atribuido a los segundos; en este sentido, ver por ejemplo, HABERMAS (2008) pp. 148149. El contenido normativo activo de los derechos políticos connota que su ejercicio supone la participación de sus titulares en la formación de la voluntad estatal en los órdenes jurídicos democráticos, principalmente a través de la elección de representantes mediante sufragio; Entre otros, destacan este aspecto, VV.AA. (KelSEN (1991) pp. 150-152; HeSSE (2001) pp. 90-91; AlEXy (2007) p. 231). Así, la consideración de los derechos civiles y los políticos como derechos de abstención supone poner entre paréntesis el papel que estos últimos tienen en la constitución de la voluntad estatal.

5 VV.AA. (Bobbio (2009) pp. 543-544; Peces-Barba (1999a) pp. 155 y 160 y ss.; Ferrajoli (2009) p. 108; Arango (2005) p. 37; Calvo (2009) p. 205).

${ }^{6}$ Un derecho subjetivo no es otra cosa que el reflejo de una obligación de otro u otros, la cual puede consistir en una abstención o una prestación; KeLSEN (1991) pp. 139-142. Y el indicio o pista que en el lenguaje jurídico ordinario sugiere una limitación de la expresión "derecho" (subjetivo) en la dirección de un significado definido y apropiado consiste en el "deber correlativo"; HoHFeLD (1992) pp. 47-52. Sobre la coincidencia entre el concepto kelseniano de derecho reflejo y el concepto hohfeldiano de derecho subjetivo, ver por ejemplo CrUZ (2007) p. 37.

7 Tener un derecho pasivo significa tener derecho a que se respete una situación o a recibir algo por parte de otro; Cruz (2007) p. 24. Por esto Kelsen critica que el "ejercicio" de los derechos sea identificado con la conducta correspondiente del individuo en cuyo respecto existe la obligación y rechaza la distinción entre derechos personales y reales; KeLSEN (1991) pp. 140 y 143.

8 VV.AA. (GUASTINI (1999) pp. 185-189; SQuella (2000) p. 518).
} 
más extrema, se sostiene que los derechos sociales de prestación no son derechos subjetivos en sentido jurídico sino meros beneficios o servicios sociales, porque no se encuentran judicialmente garantizados ${ }^{9}$. Este argumento se sustenta en el concepto kelseniano de derecho subjetivo en sentido técnico. De acuerdo con él, un derecho subjetivo es un derecho reflejo provisto de la potestad de entablar un reclamo judicial frente al incumplimiento de la obligación que el derecho refleja ${ }^{10}$, esto es, una conjunción de los conceptos hohfeldianos de derecho subjetivo y potestad o competencia ${ }^{11}$.

Las dos más importantes líneas argumentales por cuyo intermedio se ha procurado la equiparación de los derechos sociales con los derechos liberales se sustentan en una crítica a los dos conceptos de derecho subjetivo recién mencionados.

La primera de estas líneas argumentales se construye a partir de una crítica al concepto de derecho subjetivo reflejo, y comprende dos argumentos. De acuerdo con el primer argumento, un derecho fundamental no es el reflejo de una obligación de abstención o de prestación porque todos los derechos implican obligaciones de prestación. De acuerdo con el segundo argumento, un derecho fundamental no es el reflejo de una obligación de abstención o de prestación, porque todos los derechos consisten en un conjunto de obligaciones de abstención y de prestación.

La segunda línea argumental se deriva de la crítica al concepto de derecho subjetivo en sentido técnico, y también comprende dos argumentos. De acuerdo con el primer argumento, los derechos sociales son susceptibles de tutela judicial y, por tanto, derechos "verdaderos". De acuerdo con el segundo argumento, los derechos sociales no son meros beneficios o servicios sociales sino derechos subjetivos en sentido jurídico, independientemente de si están garantizados y de la forma que adopte esta garantía.

En este trabajo se analizan críticamente estas líneas argumentales con el propósito de mostrar que, aunque ellas logran reducir la distancia que separa a estas dos categorías de derechos fundamentales, no consiguen el objetivo que se proponen.

\section{EL CARÁCTER PRESTACIONAL DE TODOS LOS DERECHOS FUNDAMENTALES Y SU RECONSTRUCCIÓN COMO UN CONJUNTO DE OBLIGACIONES DE ABSTENCIÓN Y DE PRESTACIÓN COMO ARGUMENTOS PARA LA EQUIPARACIÓN DE LOS DERECHOS LIBERALES Y LOS DERECHOS SOCIALES}

En la línea argumental que aquí se presenta, pueden identificarse dos argumentos que, si bien son diferentes, niegan que el derecho subjetivo consista simplemente en el reflejo de una obligación jurídica de otro u otros.

\footnotetext{
9 Ver por ejemplo, HaRT (1983) pp. 185-186.

10 Kelsen (1991) pp. 146-149 y 152.

11 La posición activa de potestad o competencia puede definirse como aquella en la que se encuentra el individuo de cuya voluntad depende decisivamente la modificación de determinadas relaciones jurídicas; HOHFELD (1992) pp. 67-80.
} 
El primero de estos argumentos niega que el carácter prestacional deba atribuirse exclusivamente a los derechos sociales. Sobre la base de un concepto amplio de prestación y de la distinción entre prestaciones en sentido estricto y en sentido amplio, se sostiene que todos los llamados derechos fundamentales son de prestación. Los derechos civiles y políticos no consistirían solamente en obligaciones estatales negativas, sino también en obligaciones estatales positivas de realizar prestaciones normativas. A su turno, los llamados derechos sociales no consistirían solamente en obligaciones a prestaciones fácticas del Estado sino también en obligaciones estatales positivas de carácter normativo. Un derecho fundamental no podría entonces definirse como el reflejo de una obligación jurídica sino como el reflejo de un conjunto de obligaciones.

El segundo argumento incorpora al primero pero llega más lejos, desde el momento en que concluye que todos los derechos fundamentales consisten en un conjunto de obligaciones negativas y positivas del Estado. Así, un derecho fundamental no podría definirse como el reflejo de una obligación jurídica (de abstención o de prestación) sino como el reflejo de un conjunto de obligaciones de abstención y de prestación.

A lo primero que debe entonces prestarse atención es al argumento, según el cual el carácter prestacional no es exclusivamente atribuible a los derechos sociales.

Prieto Sanchís, por ejemplo, destaca que todos los derechos requieren de prestaciones en sentido amplio. Mientras los derechos prestacionales en sentido estricto son prestacionales por naturaleza, pues se refieren a bienes o servicios económicamente evaluables, como subsidios de paro, enfermedad o vejez, sanidad, educación y vivienda, los derechos civiles y políticos se benefician de las técnicas prestacionales, en la medida en que el Estado cumple con obligaciones positivas de realizar prestaciones normativas en relación con su protección y ejercicio ${ }^{12}$.

Este argumento permite refutar la exclusividad con que a los derechos sociales suele atribuirse, tanto un carácter prima facie (no definitivo), como un carácter costoso (no gratuito). En el primer caso, argumentando que la configuración de todos los derechos siempre depende de ulteriores precisiones institucionales y no de su mero enunciado. Y en el segundo caso, aduciendo que todos los derechos implican $\operatorname{costos}^{13}$, además de que la eventual diferencia en ellos no podría traducirse en una diferencia ontológica ${ }^{14}$.

Se debe notar que, de acuerdo con este argumento, se reconoce la posibilidad de relativizar la distinción entre derechos liberales y sociales al precio de reconocer que ella se mantiene en dos sentidos importantes: (i) los derechos sociales (y no los derechos liberales) consisten en obligaciones de prestaciones fácticas; y (ii) los derechos liberales (y no los derechos sociales) consisten en obligaciones de abstención.

Por lo mismo, a pesar de considerar que en el fondo la técnica prestacional plantea problemas semejantes, tanto en los derechos prestacionales por naturaleza, como en los que eventualmente solo se benefician de la misma, Prieto Sanchís enfatiza que, desde la perspectiva de la teoría de los derechos y de los propios retos políticos y jurídicos que hoy plan-

\footnotetext{
12 Prieto (1998) pp. 74-76.

13 Holmes y Sunstein (2011) pp. 135-154.

14 VV.AA. (Hierro (2007) pp. 180-194; Ruiz (1994) pp. 659-662).
} 
tea la realización del programa constitucional, la discusión debiera centrarse en el capítulo de los derechos prestacionales en sentido estricto. Más concretamente, en si la caracterización básica de los derechos fundamentales como obligaciones estatales capaces de cimentar posiciones subjetivas aun en contra de la mayoría, esto es, al margen y por encima de la ley, puede hacerse extensiva a los derechos que no generan un deber de abstención o de prestaciones meramente jurídicas, sino deberes positivos de dar bienes o servicios o de realizar actividades que, si se tuvieran medios, los sujetos podrían obtener en el mercado ${ }^{15}$.

En una línea semejante, Alexy distingue los derechos de defensa del ciudadano frente al Estado (derechos a acciones negativas u omisiones del Estado) de los que considera su contrapartida exacta: los derechos a acciones positivas del Estado (derechos a recibir prestaciones del Estado en un sentido amplio). Estos últimos comprenderían derechos de protección, derechos a la organización y al procedimiento y derechos prestacionales en sentido estricto o derechos sociales. Y todos ellos constituirían relaciones triádicas entre el titular del derecho fundamental, el Estado y una acción positiva de este, además de que compartirían problemas que no recaen en absoluto, o al menos no con la misma intensidad, sobre los derechos a acciones negativas. Mientras estos últimos impondrían límites al Estado en la persecución de sus fines, aquellos le impondrían la persecución de ciertos objetivos. Los derechos sociales constituirían, así, un sector importante de los derechos prestacionales en sentido amplio pero no agotarían su ámbito ${ }^{16}$.

Según la relevancia o irrelevancia que la forma jurídica de la ejecución tiene para su satisfacción, los derechos a acciones estatales positivas podrían entonces dividirse en dos grupos: aquellos cuyo objeto es una acción normativa y aquellos cuyo objeto es una acción fáctica ${ }^{17}$. Y aunque en relación con ambos grupos se plantearía el problema de saber si, y en qué medida, ciertos derechos subjetivos constitucionales de los ciudadanos pueden y deben imponer al Estado la obligación de perseguir ciertos fines ${ }^{18}$, los derechos prestacionales en sentido estricto son definidos, en términos semejantes a los de Prieto Sanchís, como derechos del individuo frente al Estado a algo que, si el individuo tuviera los medios financieros y encontrase en el mercado una oferta suficiente, podría obtener también de los particulares ${ }^{19}$.

La distinción entre derechos prestacionales en sentido amplio y en sentido estricto permite entonces continuar considerando a los derechos sociales como una categoría diferente a la de los derechos liberales. Mientras exclusivamente los primeros consisten en obligaciones de prestaciones fácticas, solamente los segundos consisten en obligaciones de abstención.

El segundo argumento que se debe analizar es aquel que, a partir del carácter prestacional de todos los derechos fundamentales, sostiene que todos ellos consisten en un conjunto de obligaciones negativas y positivas del Estado.

De acuerdo con Cruz Parcero, no resulta difícil ilustrar los problemas de la tesis que califica a los derechos liberales como derechos de abstención y a los derechos sociales como

15 Prieto (1998) pp. 75-76 y 80-81. En el mismo sentido, en Chile, VV.AA. (Silva (2012) p. 46; Núñez (2012) pp. 113-115 y 121-122).

16 Alexy (2007) pp. 383-384, 391-394, 443 y 454.

17 Alexy (2007) p. 171.

18 Alexy (2007) p. 393.

19 Alexy (2007) p. 393. 
derechos de prestación, cuando se advierte que el conjunto de obligaciones que involucra un derecho calificado como social incluye algunas importantes obligaciones negativas. En sus propias palabras: "Por ejemplo, cuando hablamos del derecho a la educación pensamos inmediatamente en la obligación positiva del Estado de impartir educación, construir escuelas, pagar a los maestros, dar becas, etc; pero, a su vez, el Estado tiene obligaciones pasivas de no empeorar la educación, de no expulsar a los niños de las escuelas, de no negar el acceso a la educación (en ciertas circunstancias), de no cobrar cuotas de inscripción o colegiatura cuando la educación es gratuita, etc." ${ }^{20}$.

En la misma línea, se sostiene que son muchos los derechos que implican dimensiones abstencionistas y prestacionales. El derecho a la salud, por ejemplo, no solo implicaría el respeto a unas determinadas condiciones vitales (eliminando agresiones), sino también la organización de un sistema público de salud que, desde el punto de vista asistencial, asegurare su satisfacción. De modo semejante, el derecho a la educación no solo implicaría la libertad de elegir la formación que se prefiera, de acuerdo con las concepciones personales, sino también la articulación de un sistema público de educación ${ }^{21}$.

Un paso más adelante, Eide sostiene que los derechos humanos imponen tres niveles de obligaciones a los Estados. En el primer nivel, deberían respetar a los individuos su libertad de actuar y de usar sus propios recursos en la satisfacción de sus necesidades. En el segundo nivel, las obligaciones del Estado consistirían en la protección de la libertad de acción y de uso de los recursos frente a terceros. En el tercer nivel, la obligación estatal sería de realización y se cumpliría, de un lado, por la vía de facilitar de diversas formas y, de otro, a través de la directa provisión, consistente en poner a disposición lo que se requiera para la satisfacción de necesidades básicas, tales como comida, o bien recursos que pudieren ser usados para ello cuando no existieren otras posibilidades ${ }^{22}$.

De modo similar que Alexy y Prieto Sanchís, Abramovich y Courtis observan que, aun los derechos que parecen ajustarse más fácilmente a la caracterización de "obligación negativa”, conllevan una intensa actividad estatal que corresponde a funciones cuyo cumplimiento reclama obligaciones positivas caracterizadas por la erogación de recursos, y no la mera abstención del Estado. Pero su conclusión es que, tanto la estructura de los derechos civiles y políticos, como la de los derechos sociales, podría ser caracterizada como un complejo de obligaciones positivas y negativas del Estado. Las diferencias serían de grado más que sustanciales y la adscripción de un derecho a uno de los dos catálogos tendría un valor heurístico, ordenatorio o clasificatorio ${ }^{23}$.

Siguiendo a Eide y a Van Hoof, Abramovich y Courtis proponen un esquema de tres niveles de obligaciones que serían comunes a todos los derechos independientemente de su adscripción al conjunto de una u otra categoría. Las obligaciones serían de respeto, protección y satisfacción, y estas últimas incluirían las obligaciones que Van Hoof denomina de garantía y de promoción. En opinión de estos autores, este esquema serviría para debilitar

\footnotetext{
${ }^{20}$ Cruz (2007) p. 76. En el contexto local, ver por ejemplo, Nogueira (2010) pp. 24-27 y 38.

21 Ansuátegui (2010) p. 57.

22 EIDE (2001) pp. 23-24.

23 Abramovich y Courtis (2004) pp. 20, 23-31. En sentido semejante, por ejemplo, Rossetti (2010) pp. 114-116).
} 
la distinción tajante entre los derechos civiles y políticos, por un lado, y los derechos sociales, por el otro ${ }^{24}$.

Todos los autores cuya opinión ha sido revisada coinciden en cuanto consideran que todos los derechos fundamentales son prestacionales, y en cuanto distinguen las prestaciones fácticas de las prestaciones normativas y, por tanto, entre prestaciones en sentido estricto y en sentido amplio. Las diferencias surgen cuando se trata de precisar el contenido específico de los derechos sociales.

\section{LA JUSTIFICACIÓN DE LAS LIMITACIONES AL CONTENIDO DE LOS DERECHOS SOCIALES Y DE SU DEFINICIÓN COMO DERECHOS SUBJETIVOS DE PRESTACIÓN}

La extensión del significado de las llamadas obligaciones positivas no impide que, entre dichas obligaciones, puedan distinguirse las que son de prestación en sentido estricto de las que, en cambio, lo son en sentido amplio. Y si las prestaciones en sentido estricto (fácticas) siguen siendo una característica exclusiva de los derechos sociales, sigue habiendo una razón para distinguirlos de los derechos liberales.

Por otra parte, la aceptación de la extensión del significado de las obligaciones positivas, no autoriza a concluir que el contenido de los derechos sociales incluye obligaciones de abstención. Si subsisten las razones para excluirlas, subsisten las razones para distinguir a estos derechos de los derechos liberales que, con carácter exclusivo, podrían caracterizarse como derechos a acciones negativas del Estado.

\subsection{Justificación de la eXClusión de los Deberes Que NO CONSISTEN EN PRESTACIONES FÁCTICAS DEL CONTENIDO DE LOS DERECHOS SOCIALES: EL SIGNIFICADO COMÚN DE “PRESTACIÓN"}

La definición de los derechos sociales como posiciones que solo reflejan deberes que consisten en prestaciones fácticas o materiales, se justifica simplemente porque todos los derechos requieren prestaciones normativas.

Todo derecho fundamental es de prestación, desde el momento en que exige al menos un reconocimiento en forma de constitucionalización y un desarrollo legislativo por parte de los poderes públicos. Al utilizarse este argumento para defender la desaparición de la distinción entre derechos liberales y derechos sociales, posiblemente se esté ampliando de manera excesiva la comprensión común de la idea de prestación ${ }^{25}$.

Precisamente porque los derechos sociales son prestacionales en un sentido específico, y diferente de aquel en el cual todos los derechos lo son, es que ha podido formularse el

\footnotetext{
${ }^{24}$ Asimismo ponen de relieve que las obligaciones positivas del Estado no se agotan en las que consisten en disponer de reservas presupuestarias para ofrecer una prestación. Aquellas comprenderían la de establecer algún tipo de regulación, sin la cual el ejercicio de ciertos derechos carece de sentido; la de que esta regulación limite o restrinja las facultades de las personas privadas o les imponga obligaciones de algún tipo; y la de proveer bienes o servicios a la población, que supone el establecimiento una relación directa entre el Estado y el beneficiario de la prestación; ABRAMOVICH y CourTis (2004) pp. 31-36.

25 Ansuátegui (2010) pp. 57-58.
} 
argumento según el cual, a diferencia de los derechos civiles y políticos, los derechos sociales involucrarían, en la mayor parte de los casos, una condicionalidad económica como parte estructural de su contenido normativo, pues este no solo requeriría de recursos jurídicos sino también económicos ${ }^{26}$.

Esto no significa que las prestaciones jurídicas no impliquen costos económicos. Los criterios para distinguirlas de las prestaciones fácticas son, por un lado, el tipo de relación que se establece entre el Estado y el beneficiario y, por otro, la relevancia o irrelevancia que la forma jurídica tiene para la satisfacción del derecho. Mientras las obligaciones que consisten en proveer bienes o servicios a la población suponen el establecimiento de una relación directa entre el Estado y el beneficiario de la prestación ${ }^{27}$, en el caso de las demás obligaciones prestacionales se interpone, entre el acreedor y el deudor, un conjunto de normas de organización carentes de exigibilidad que, a su vez, generan una multiplicidad de obligaciones jurídicas de distintos sujetos, cuyo cumplimiento conjunto es necesario para la plena satisfacción del derecho ${ }^{28}$. A su turno, mientras para la satisfacción de los derechos que reflejan obligaciones que consisten en proveer bienes y servicios, la forma jurídica es irrelevante ${ }^{29}$, en las demás obligaciones positivas ocurre lo contrario.

Lo relevante es que, aunque tanto las prestaciones fácticas como las normativas implican costos económicos, las diferencias apuntadas permiten distinguir a los derechos sociales de los demás derechos fundamentales.

Al respecto, es importante notar que, incluso quienes procuran refutar la identificación entre derechos sociales y derechos de prestación reconocen, al menos implícitamente, que a los primeros se asocia una idea de prestación diferente a la que subyace a las obligaciones estatales positivas que se dirigen modificar la forma de organización social que hace imposible el cumplimiento de los derechos sociales. Y esta diferencia es similar a la que existe entre la idea de abstención característicamente vinculada a los derechos liberales y la idea de prestación que subyace a las obligaciones estales positivas que hacen posible el ejercicio de estos derechos.

Lema, por ejemplo, sostiene que el hecho que el titular no pueda acceder por sus propios medios a la satisfacción de uno de sus derechos sociales, depende del marco socioeconómico y es, de por sí, una vulneración de ese derecho. La obligación del Estado se extendería entonces más allá de garantizar la prestación, debiendo consistir en una actividad positiva dirigida a poner las condiciones de un sistema socioeconómico no excluyente, es decir, a configurar el orden social ${ }^{30}$. Pero, al afirmar esto, está admitiendo que hay un sentido en el cual todos los derechos son prestacionales, y que es diverso del sentido en que, básica y específicamente, los derechos sociales son considerados derechos de prestación.

\footnotetext{
26 Aldunate (2008) pp. 58-59. En contra, por ejemplo, Zúñiga (2012) p. 49.

27 Aunque la obligación de proveer de bienes y servicios puede ser exclusiva del Estado, también cumplirse a través de formas de cobertura mixta que, además del aporte estatal, incluya regulaciones en que los privados se vean afectados a través de restricciones, limitaciones u obligaciones; ABramovich y CourTis (2004) pp. 32-36.

28 Prieto (1998) pp. 78-79.

29 Alexy (2007) p. 171.

30 Lema (2010) p. 90, quien a estos efectos, se preocupa de recordar el, su juicio, olvidado artículo 28 de la Declaración Universal de Derechos Humanos.
} 
Dejando a un lado el carácter prestacional de todos los derechos, todavía se podría esgrimir que los derechos sociales no se reducen a los derechos de prestación, y que estos no se reducen a los derechos sociales.

Un ejemplo de lo primero serían los, frecuentemente considerados sociales, derechos a la huelga y a la sindicación, en la medida en que su satisfacción exigiría, en lugar de una prestación, el reconocimiento de un ámbito de libre decisión o no interferencia a favor del titular ${ }^{31}$.

Un ejemplo de lo segundo podría encontrarse en el llamado derecho a la asistencia letrada. Al respecto, se argumenta que, pese a tratarse de un derecho de prestación (que supone la obligación estatal proporcionar un abogado a quien no posee los medios para procurárselo por sí mismo), estaría incluido en la primera generación de derechos civiles. En este sentido, se enfatiza que no es un caso que se presente exclusivamente por la falta de medios económicos para costear un abogado. Pues también entraría en juego cuando el afectado no quisiere designarlo, puesto que se trataría de una necesidad del sistema procesal garantista ${ }^{32}$.

Sin pretender desconocer las circunstancias históricas que contribuyeron a la aparición de las diferentes reivindicaciones de derechos ${ }^{33}$, a ambas cuestiones se puede responder afirmando que el argumento que distingue a los derechos sociales de los liberales no es histórico ni generacional. Desde el punto de vista según el cual los derechos sociales reflejan obligaciones estatales positivas fácticas o materiales, el derecho a contar con asistencia letrada es un derecho social, en la medida en que una norma jurídica obliga al Estado a realizar la correspondiente prestación material ${ }^{34}$, mientras los derechos a la huelga y a la sindicación no podrían ser incluidos en esta categoría ${ }^{35}$.

Esto conduce al examen de la segunda limitación del contenido de los derechos sociales, esto es, su calificación como derechos que no reflejan deberes de abstención.

\subsection{Justificación de la eXClusión de las Obligaciones de ABSTENCiÓn del} CONTENIDO DE LOS DERECHOS SOCIALES: EL DERECHO SUBJETIVO COMO PROTECCIÓN DEL DERECHO OBJETIVO

Frente a la tesis que afirma que existen derechos fundamentales de abstención y de prestación según sea el tipo de obligación correlativa, se sostiene, como hemos visto, que todos los derechos fundamentales reflejan un conjunto de obligaciones negativas y positivas ${ }^{36}$.

\footnotetext{
31 VV.AA. (Ansuátegui (2010) p. 57; Martínez De Pisón (2009) p. 91).

32 Peces-Barba (1999b) p. 60.

33 Sobre el punto, Marshall (1998).

34 La universalidad de este derecho sería defendible argumentando que se confiere a todos los sujetos que se encuentren en las mismas circunstancias, o bien esgrimiendo que su titularidad es potencial, aunque las circunstancias que determinarían su aparición fueran estadísticamente menos probables que otras como, por ejemplo, las de llegar a la tercera edad; Ruiz (1994) p. 663.

35 La tradicional calificación de los derechos de huelga y sindicación como derechos sociales ha generado dificultades teóricas que algunos enfrentan reconociendo precisamente que ellos no pueden ser caracterizados esencialmente como derechos que generan obligaciones positivas al Estado, y que su adscripción a este catálogo se explica por argumentos históricos; ABRAMOVICH y CourTis (2004) p. 27.

36 Algunos autores llegan incluso más lejos al considerar que los derechos fundamentales resultarían mejor explicados como un conjunto de todas las posiciones jurídicas subjetivas activas del modelo de análisis de Hohfeld; VV.AA. (Hierro (2000) p. 356; Cruz (2004) pp. 76 y 78 y Cruz (2007) pp. 36-38; Laporta (1987)
} 
Esta forma de entender los derechos subjetivos es problemática desde una perspectiva analítica, puesto que conduce a confundir las posiciones jurídicas subjetivas conferidas por el derecho objetivo para la protección de bienes con los bienes, intereses o voluntades que son objeto de esa protección. Bajo la noción de "un conjunto de obligaciones de abstención y de prestación” se oculta la idea de que los derechos fundamentales son los bienes que a cada individuo corresponden en justicia ${ }^{37}$, mientras que, analíticamente, es indispensable distinguir las relaciones puramente jurídicas de los hechos físicos y psíquicos que las hacen surgir ${ }^{38}$. No interesa lo que el derecho objetivo protege (la sustancia) sino la protección (la forma ${ }^{39}$.

Desde este punto de vista, es incorrecto hablar, por ejemplo, de un "derecho a la salud". Puede que el ordenamiento jurídico confiera a los individuos un derecho subjetivo a que el Estado no dañe su salud, un derecho subjetivo a que el Estado no impida su libre elección en materia de salud, un derecho subjetivo a que el Estado no le impida el igualitario acceso a las acciones de salud y un derecho a que el Estado realice determinadas prestaciones en materia de salud. Obviamente los derechos subjetivos mencionados, así como sus correlativos deberes de abstención y de prestación, son interdependientes en orden a lograr la pretendida protección de la salud, que es un bien, y no un derecho.

Aun cuando, desde esta perspectiva, se pueda justificar la diferenciación de los derechos liberales y los derechos sociales (considerándolos, respectivamente, como derechos de abstención y derechos de prestación), parece obvio que esta diferenciación no constituye por sí sola una justificación para afirmar la imposibilidad de equiparar estas categorías de derechos. Por otra parte, la opinión según la cual los derechos fundamentales consisten en un conjunto de obligaciones de abstención y de prestación, que actualmente parece ser dominante, no ha logrado la pretendida equiparación de los derechos sociales con los derechos liberales.

La mejor prueba de ello se encuentra en la copiosa elaboración de argumentos que, para defender dicha equiparación, esgrimen la importancia de distinguir a los derechos de sus garantías, la existencia de otras formas de exigibilidad y la justiciabilidad de los derechos sociales, todos los cuales asumen que los derechos liberales y sociales son, respectivamente, derechos de abstención y de prestación. El análisis debe desplazarse entonces a estos argumentos.

\section{LA IMPORTANCIA DE DISTINGUIR A LOS DERECHOS DE SU GARANTÍA JUDICIAL, OTRAS FORMAS DE EXIGIBILIDAD, Y LA JUSTICIABILIDAD DE LOS DERECHOS SOCIALES COMO ARGUMENTOS PARA SU EQUIPARACIÓN CON LOS DERECHOS LIBERALES}

La línea argumental que a continuación se examina se deriva de la crítica al concepto de derecho subjetivo que supone la objeción a la juridicidad de los derechos sociales o, a lo

pp. 23-30). En la misma línea, pero teniendo como referencia modelos diferentes al de Hohfeld, VV.AA. (Alexy (2007) pp. 162-163 y 214-218; DiciotTi (2004) p. 738-739).

37 Sobre esta confusión y la posibilidad de interpretarla como una caprichosa retrospección hacia la idea romana clásica del derecho, ver ArRIAGADA (2012) pp. 69-70 (nota No46 de ese trabajo).

38 Hohfeld (1992) p. 31.

39 KeLSEN (1987) pp. 510 y 539. 
menos, su sindicación como derechos "sobre el papel". En este sentido, alguien tiene un derecho subjetivo cuando tiene un derecho reflejo provisto de la potestad de entablar un reclamo frente al incumplimiento de la obligación que el derecho refleja, o alguien tiene un derecho subjetivo "verdadero" cuando este justiciable, es decir, susceptible de tutela jurisdiccional.

Veamos primero la manera en que se intenta responder a la objeción que se formula a la autenticidad de los derechos sociales.

\subsection{LOS DERECHOS SOCIALES COMO DERECHOS “VERDADEROS”}

La razón por la cual los derechos sociales no serían justiciables y, por tanto, derechos "verdaderos" es, según Guastini, que tanto las obligaciones correspondientes a tales derechos, como los sujetos obligados, no se encuentran bien determinados ${ }^{40}$. El problema podría entonces sintetizarse en las dos siguientes preguntas en relación con los derechos sociales: “¿A qué obligan?” y “¿A quién obligan?”.

En relación con la primera de estas preguntas, el problema parece residir en que, a diferencia de las obligaciones de no hacer, las obligaciones de hacer podrían cumplirse de diversos modos.

Bernal, por ejemplo, considera que la diferencia específica de los derechos sociales pareciera estar en la manera como se determina su objeto (una prestación a cargo del Estado) y en la manera en que se precisa cuándo existe una vulneración de estos derechos. Como las disposiciones que establecen derechos sociales no precisarían con claridad, en todos los casos, cuál es la prestación mediante la cual se satisface el derecho, tampoco aparecería determinado qué es lo constitucionalmente contrario a aquello que el derecho exige, es decir, cuándo se vulnera el derecho social. Esta peculiar indeterminación del objeto no se presentaría del mismo modo en los derechos de libertad porque, como en estos últimos la conducta debida es una abstención, lo constitucionalmente contrario al derecho habría de ser cualquier tipo de conducta ${ }^{41}$.

No resulta difícil notar que la indeterminación que se asocia a la forma de cumplimiento de la obligación es más bien una característica de las obligaciones impuestas por las llamadas "normas teleológicas", que prescriben la consecución de un fin sin establecer las conductas idóneas para obtenerlo ${ }^{42}$, de modo que la elección del modo en que se obtiene el fin es dejada a la discreción del destinatario de la norma ${ }^{43}$.

\footnotetext{
40 Guastini (1999) pp. 185-186.

41 Bernal (2004) p. 116.

42 VV.AA. (Guastini (1999) p. 115; Arriagada (2010) pp. 37-45).

43 Atienza y Ruiz Manero (2004) p. 8. Más precisamente, el criterio para distinguir a una norma de fin es la completa discrecionalidad que ella deja al destinatario para decidir qué conductas (acciones u omisiones) realizar para la consecución del fin que la norma prescribe, de modo que el o los obligados por la norma son quienes en realidad determinan de qué forma han de conducirse para cumplir con lo prescrito. La diferencia con las normas de conducta reside en que, en estas, el destinatario carece de discrecionalidad respecto de cómo conducirse para cumplir con lo prescrito, pues la única forma de hacerlo es mediante una o más conductas que la norma establece, sin perjuicio que tales conductas pudieren, en el plano de lo más concreto, cumplirse en más de una forma. Si bien puede parecer que esto último atenúa un poco el rigor de la distinción, el grado de discrecionalidad con que eventualmente pudiere contar el destinatario de una norma de conducta seguiría contrastando con la absoluta discrecionalidad que caracteriza a las normas de fin. Por supuesto que este criterio no
} 
En este sentido, Guastini sostiene que, a causa de su indeterminación, las disposiciones que confieren derechos sociales suelen ser interpretadas como normas teleológicas dirigidas al legislador, el cual no tendría ninguna obligación precisa respecto de la elección de los medios a emplear para perseguir la finalidad determinada en la norma ${ }^{44}$. Y de acuerdo con Cruz Parcero, la frecuencia con que estas normas son usadas para proteger esta clase de derechos habría influido en la creencia común de que todas las normas relacionadas con derechos sociales son de este tipo. Muchas de las concreciones centrales de los derechos sociales consistirían en reglas de fin y directrices, y esto se explicaría porque, como muchos de los objetivos que una sociedad busca alcanzar tienen que llevarse a cabo considerando distintos factores y dados ciertos contextos, el legislador trasladaría las decisiones a otros funcionarios, que entonces llevarían a cabo la selección de los medios adecuados ${ }^{45}$. El gran problema de la justiciabilidad sería poder establecer criterios que pudieran servir para controlar el comportamiento de los destinatarios de las normas de fin; tanto sus poderes discrecionales como el ejercicio concreto que hacen de ellos ${ }^{46}$.

Lo relevante es que no existe ninguna razón para negar que este tipo de indeterminación afecte a las disposiciones que prescriben obligaciones negativas ${ }^{47}$. Piénsese, por ejemplo, en las que expresan prohibiciones de discriminación. Al margen del problema de las condiciones de aplicación de la norma -cuestión que en este caso se deja de lado-, difícilmente podríamos decir que su formulación permite saber cuál es el comportamiento que el destinatario debe omitir. Resulta entonces plausible interpretar que una disposición de esta clase prohíbe cualquier conducta que tenga como resultado la discriminación, entendida esta como un estado de cosas y la norma en cuestión como una que prohíbe la consecución de un objetivo ${ }^{48}$.

Así, cada vez que una disposición no especifica con claridad cuáles son todas las conductas que se encuentran prohibidas, se produce, al menos en la parte no especificada, una indeterminación cualitativamente semejante a la que suele afectar a las obligaciones positivas que se imponen al Estado a través de la formulación de normas teleológicas.

Es cierto que cuando la conducta debida es una abstención, en principio, se podría decir que cualquier tipo de conducta es constitucionalmente contraria a la satisfacción del derecho ${ }^{49}$. Pero también es cierto que muchas de las disposiciones que confieren derechos

considera la discrecionalidad con que el destinatario de la norma puede contar respecto de la verificación de las condiciones de su aplicación; su foco está solamente en lo prescrito; ArRIAGADA (2010) pp. 66-69.

44 Guastini (1999) p. 189.

45 CRuz (2007) pp. 73 y 84.

46 Cruz (2007) pp. 94-95. Como no es posible profundizar en este tipo de análisis, baste hacer presente que no existe una relación necesaria entre las normas de fin y la posibilidad de graduar el cumplimiento de lo prescrito, así como tampoco la hay entre aquellas normas y la necesidad o exigencia de optimizar dicho cumplimiento (mandatos de optimización). Sobre este punto, así como en general sobre la posibilidad, la imposibilidad y la necesidad de graduar el cumplimiento de las normas de fin y de las normas de conducta, ver ArRIAGADA (2010) pp. 51-69.

47 CRUZ (2007) p. 83.

48 Arriagada (2010) pp. 45-51.

49 Bernal (2004) p. 116. 
fundamentales son vagas o generales, a lo que debe añadirse que, entre sus posibles significados, se producen conflictos ${ }^{50}$.

El propio Bernal admite que todas las disposiciones que establecen derechos en una Constitución son indeterminadas porque no especifican con claridad el conjunto de prohibiciones, mandatos, permisos y competencias que prescriben. Y esta sería la causa de que, frente a todos los derechos fundamentales, la lucha ideológica se hubiere desplazado desde el ámbito de la política hacia la interpretación constitucional y, por consiguiente, desde el parlamento hacia los tribunales constitucionales ${ }^{51}$.

Estas consideraciones solo pretenden ilustrar que, en contra de la objeción a la justiciabilidad de los derechos sociales, se puede argumentar que los problemas que se derivan de la indeterminación de las disposiciones que los consagran son semejantes en los derechos liberales, de modo que las dificultades que pudieren surgir con motivo del mayor grado de indeterminación de algunas disposiciones tendría que ser resuelto en el nivel interpretativo. Como observa Alexy, los derechos fundamentales son lo que son, sobre todo, a través de la interpretación ${ }^{52}$. Y por lo mismo, se podría concluir que la falta de precisión de los derechos sociales se debe precisamente a que no han sido garantizados judicialmente, como consecuencia de lo cual no ha podido desarrollarse una práctica interpretativa respecto de los mismos ${ }^{53}$.

La objeción vinculada con la segunda pregunta formulada en relación a los derechos sociales, esto, “¿A quién obligan?”, parece fundarse en que, en el caso de los derechos de abstención, el sujeto obligado resultaría siempre identificable una vez que se ha violado la obligación de abstención, siempre que por supuesto se hubiere establecido que lo ejecutado es constitucionalmente contrario a dicha obligación. A falta de determinación expresa del sujeto obligado, y atendido que los derechos fundamentales se tienen en contra del Estado, sería plausible interpretar que la prohibición está dirigida a cualquier autoridad pública.

La violación de las obligaciones positivas consistente, en cambio, en una inacción sería, por el contrario, difícilmente imputable a un sujeto determinado, a falta de una norma que expresamente lo designare como obligado y respaldare su cumplimiento con una sanción al punto que la ausencia de una norma clara en este sentido, podría llevar a concluir que solo se tiene un derecho "sobre el papel". Guastini, por ejemplo, sostiene que mientras el juez constitucional podría anular toda ley que violase un derecho social (nótese que en este caso se trataría de un derecho de abstención), la omisión de proveer, por parte del legislador, estaría privada de cualquier sanción ${ }^{54}$.

Esta lectura es equivocada ${ }^{55}$. Ella confunde las dificultades que se derivan de que el Estado sea el sujeto obligado (algo que ocurre tanto en los derechos de abstención como en

50 VV.AA. (Guastini (2010) pp. 223-225 y 228-231; Peces-Barba (1999a) p. 77, Prieto Sanchís (2000) pp. 432-433 y 429-468; MORESO (2009) pp. 51-66).

51 BERNAL (2004) p. 116.

52 Alexy (2009) pp. 32-33 y 35.

53 Figueroa (2009a) pp. 330-331.

54 Guastini (1999) p. 189.

55 A ella subyace el mal entendido de que los efectos que se derivan del ejercicio de las facultades propias de la jurisdicción constitucional son equivalentes a la sanción cuya ausencia se reclama para el caso de los derechos 
los de prestación) con las implicaciones que tendrían las sentencias de los tribunales con jurisdicción constitucional, en el caso que los derechos sociales de prestación estuvieren garantizados judicialmente, a pesar de la indeterminación de su contenido. Por lo demás, es casi seguro que esta es la preocupación que siempre justifica el uso del argumento de la indeterminación, tanto del contenido, como del sujeto obligado en los derechos sociales.

$\mathrm{Al}$ respecto, se han formulado diferentes objeciones, entre las que cabe destacar la falta de capacidad o preparación técnica de los jueces y su falta de legitimidad política (al no ser electos democráticamente ni ser responsables políticamente) para intervenir en decisiones relativas a la distribución de recursos públicos ${ }^{56}$, las cuales pueden reunirse bajo la idea más general de que los derechos sociales comportan mandatos para políticas públicas y los jueces no pueden hacer política ${ }^{57}$. De no ser estas las auténticas objeciones a la justiciabilidad de los derechos sociales, no se explicaría por qué no se plantean también a propósito de los derechos liberales afectados por el mismo tipo de indeterminación; sobre todo si se tiene en cuenta que las objeciones que solo se formulan desde la democracia apuntan, en general, al atrincheramiento de derechos en las constituciones ${ }^{58}$.

No obstante, y dado que se insiste en que la crítica sería específicamente pertinente en relación con los derechos sociales (debido a que serían derechos especialmente indeterminados y, en relación con los cuales, la intervención del juez podría condicionar los criterios de distribución de recursos que se manejan un determinado contexto) conviene, como sugiere Barranco, tener en cuenta tres cuestiones: (i) Como los derechos no son absolutos, en cada caso habría que tener en cuenta las posibilidades de realización en función de la necesidad de articularlos con otros derechos y bienes constitucionales; (ii) La realización de los derechos no correspondería a los jueces, pues estos solo intervendrían cuando el ejecutivo o el legislativo hubieren incumplido sus obligaciones, además de que lo harían a instancia de parte, y (iii) Se han desarrollado fórmulas a través de las cuales los órganos de control de constitucionalidad determinan la vulneración del derecho pero mantienen en manos del legislador la reparación ${ }^{59}$.

Los argumentos expuestos muestran que la calificación de los derechos sociales como derechos "sobre el papel", sustentada en que ellos no son susceptibles de tutela jurisdiccional

sociales. Se asume, por ejemplo, que cuando un tribunal con jurisdicción constitucional invalida una ley, esta invalidación es una especie de sanción, o por decirlo en otros términos, una consecuencia jurídica desfavorable que una norma imputa al incumplimiento de una obligación. Y como en el caso del incumplimiento de una obligación positiva no hay nada que invalidar, se esgrime que falta la sanción y, como consecuencia, la ausencia de un sujeto obligado. El mismo argumento puede proyectarse a los casos en que los jueces constitucionales desaplican leyes e incluso a los casos en los cuales dejan sin efecto un acto administrativo en aplicación de una disposición constitucional que consagra un derecho fundamental. Como en tales hipótesis se supondría la infracción de obligaciones de abstención, no habría inconveniente para la protección de los derechos.

56 Para una descripción de estas objeciones, ver FigUeroA (2009b).

57 Se considera, por ejemplo, que bajo esa idea pueden subsumirse distintas razones relacionadas entre sí entre las cuales destaca las recién nombradas (falta de condiciones técnicas y falta de legitimidad democrática) a las que agrega la de que los juzgados y procedimientos que allí se desarrollan no son aptos para resolver derechos sociales, en el entendido de que los jueces no "hacen" política; RossetTi (2010) pp. 121-122.

58 Por ejemplo, Waldron (2005).

59 Barranco (2010) pp. 165-166. 
porque son indeterminados es, cuando menos, discutible a la luz de la semejante indeterminación que afecta a las disposiciones constitucionales que confieren los denominados derechos liberales. Sin embargo, ninguna de estas argumentaciones cambia el hecho de que, por regla general, los derechos sociales de prestación no se encuentran judicialmente garantizados.

En un momento en el cual la supremacía de la constitución se descubre en dos sentidos que se tratan de conjugar (como norma fundamental de garantía de derechos y libertades y como norma directiva fundamental) ${ }^{60}$, el goce de los derechos sociales (como la educación, la subsistencia o el trabajo) es presentada por Fioravanti como una típica materia de la constitución como norma directiva, bajo la idea de que el Estado se convierte en un instrumento, que solamente existe en función de un objetivo a perseguir, de valores a realizar y de necesidades a satisfacer ${ }^{61}$. Esto no significa que los derechos sociales que las constituciones promocionan se conviertan, por este hecho, en derechos protegidos o garantizados, sino más bien que, mientras algunos derechos fundamentales se garantizan, otros se promocionan precisamente porque todavía no se tienen.

Si la idea de garantizar los derechos parece satisfacerse cuando existe algún mecanismo de control constitucionalidad que los sustraiga de los poderes constituidos y que sea accionable por los titulares de los derechos, la posibilidad de extender esta misma forma de garantía a los derechos sociales presupone que estos ya se tienen. De otro modo, no habría nada que sustraer y, por tanto, nada que garantizar. Si, en cambio, la propuesta de conciliar estos dos tipos de constitución llevara implícita la sugerencia de que a la promoción exitosa debiera necesariamente seguir la garantía, estaríamos frente a auténticos derechos de abstención exigibles por la vía judicial y, en consecuencia, fuera del ámbito de los derechos sociales de prestación.

Revisemos ahora la manera en que se procura responder a la objeción que se formula a la juridicidad de los derechos sociales, es decir, a la consideración de que ellos no son derechos en sentido jurídico sino beneficios o servicios sociales.

\subsection{LOS DERECHOS SOCIALES COMO DERECHOS EN SENTIDO JURÍDICO}

Frente a la objeción que, con sustento en su falta garantía judicial, se formula a la juridicidad de los derechos sociales de prestación, se suele esgrimir la importancia de mantener diferenciados a los derechos subjetivos de sus garantías, además de la existencia de formas de exigibilidad diversas a la garantía propiamente judicial. Se concluye que las exigencias de justicia que suelen agruparse bajo el rótulo de derechos sociales son, tanto como los derechos civiles y políticos, derechos que reflejan obligaciones del Estado y, sobre esa base, se propone su equiparación.

En el extremo opuesto a la posición según la cual alguien tiene un derecho subjetivo solo en cuanto tiene la potestad de reclamar judicialmente por el incumplimiento de la obligación, puede situarse la opinión de Ferrajoli. Este autor enfatiza la necesidad de no confundir los derechos subjetivos (las expectativas positivas o negativas atribuidas a un sujeto por una norma jurídica) con sus garantías primarias (las obligaciones o prohibiciones correlativas

60 Fioravanti (2007) pp. 127-129.

61 Fioravanti (2007) pp. 129-134. 
a los derechos) o secundarias (las obligaciones de aplicar la sanción o de declarar la nulidad de las violaciones de las primeras ${ }^{62}$. Por su defectuoso sistema de garantías, los derechos sociales constituirían un ejemplo paradigmático de la disociación entre normatividad y efectividad, es decir, entre validez y vigencia ${ }^{63}$, pero indudablemente serían derechos.

Entre estos dos extremos, puede identificarse un conjunto de posiciones calificables como intermedias que se caracterizan, de un lado, porque asumen que la existencia de un derecho subjetivo depende básicamente de la existencia de una obligación correlativa y, de otro, porque no identifican la garantía de los derechos con su tutela judicial.

Cruz Parcero, por ejemplo, insiste en que el problema básico de la noción kelseniana de derecho subjetivo en sentido técnico es que restringe la posibilidad de hablar de derechos en situaciones en que no se presenta un poder jurídico o acción procesal para demandar ante un órgano (jurisdiccional o administrativo) el cumplimiento de un deber. A su parecer, Kelsen no habría distinguido los enunciados sobre derechos de los enunciados sobre protección de derechos; en otras palabras, entre un derecho y una garantía ${ }^{64}$. La acción procesal no sería más que un instrumento para la protección de los derechos sociales, no tendríamos que ver en ella la única forma de garantizar un derecho y quizás, en el caso de los derechos sociales, tampoco sería la más adecuada ${ }^{65}$.

Así, mientras de un lado, se destaca que la existencia de un derecho no puede depender exclusivamente de su exigibilidad judicial, cualquiera que sea la forma como esta sea descrita, y que lo que más bien sucede es que cuando existe un derecho este es también exigible judicialmente ${ }^{66}$, de otro, se enfatiza que los medios de exigibilidad de los derechos sociales no se agotan en las vías procesales específicamente establecidas para tutelar estos derechos ${ }^{67}$; dicho de otro modo, que la garantía de un derecho no consiste necesariamente en un mecanismo de tutela jurisdiccional ${ }^{68}$.

Con respecto a lo primero, basta tener presente el concepto kelseniano de derecho subjetivo reflejo unido a la consideración de que el otorgamiento de derechos subjetivos en sentido técnico no es una función esencial del derecho objetivo ${ }^{69}$, así como también el sig-

\footnotetext{
${ }^{62}$ Ferrajoli (2009) pp. 59 y ss.

63 Ferrajoli (2009) pp. 108-109. Sobre la disociación entre validez y vigencia, y su utilidad como un instrumento de análisis crítico, ver FERrajoli (2002) pp. 7-20.

${ }^{64}$ CRUz (2007) p. 30. Esta crítica a Kelsen no es pertinente puesto que, desde la perspectiva de este autor, el derecho subjetivo en sentido técnico no es más que uno de los sentidos en que se usa la expresión derecho subjetivo en la doctrina tradicional.

65 Cruz (2004) p. 85. Incluso Guastini admite que si bien los derechos son típicamente garantizados en sede jurisdiccional, ellos también pueden serlo, como ocurre a menudo, mediante instrumentos de otra naturaleza como las técnicas de organización constitucional reconducibles a la separación de poderes y a la creación de contrapoderes; GUASTINI (1999) p. 185.

${ }_{66}$ Alexy (2007) p. 456. En sentido semejante, en Chile por ejemplo, Nogueira (2010) p. 20.

67 Carbonell (2008) p. 46.

68 Así por ejemplo, Pérez (1984) pp. 66 y ss. En el contexto local, analiza el conjunto de garantías de los derechos económicos, sociales y culturales tratando a la justiciabilidad como un tópico independiente, NoGUEIRA (2010) pp. 39-65 y 65-75.

69 Kelsen (1991) pp. 148-149.
} 
nificado definido y apropiado que, según Hohfeld, tienen los derechos subjetivos ${ }^{70}$, unido a la importancia de que aquel sea diferenciado del concepto de potestad o competencia ${ }^{71}$.

Con respecto a lo segundo, se sostiene, por ejemplo, que de la eficacia directa de la Constitución se derivaría una potencial disponibilidad inmediata que se concreta en la posibilidad de exigir que los poderes públicos arbitren la organización y los procedimientos necesarios para dar efectividad a los derechos fundamentales, de manera que la omisión de esta obligada intervención del legislador haría emerger la eficacia directa de la norma iusfundamental, aunque fuera en su contenido mínimo o esencial. Los derechos fundamentales serían tales con independencia de quién fuera su titular y de cuál fuera la estructura en la que estén articulados, pudiendo ser derechos de esta clase, tanto los derechos de libertad y de defensa, como aquellos que se caracterizan por tener un alto contenido prestacional $^{72}$.

También sería plausible argumentar, por ejemplo, que a falta de instrumentos procesales específicos en el ordenamiento interno, las reclamaciones podrían ampararse en los instrumentos internacionales en virtud de los cuales los Estados se obligan a proveer a los individuos recursos judiciales efectivos dirigidos a la protección de sus derechos fundamentales frente a posibles violaciones.

En la misma línea puede situarse la parte que del trabajo de Abramovich y Courtis se dirige específicamente a desvirtuar la objeción de los derechos sociales como derechos exigibles. Al respecto se afirma que, para la existencia de un derecho subjetivo, basta que se tenga al menos "algún" poder de reclamo, no siendo necesario que este exista en "todos" los casos de violación ${ }^{73}$.

Otra opción identificable, y de hecho operante, se encuentra, por ejemplo, en la posibilidad de que los derechos sociales sean alegados como formas "convertidas" de propiedad, libertad o igualdad ${ }^{74}$, en la medida que estos derechos sí cuenten con un recurso destinado a su garantía judicial. La relativización de la distinción fuerte que se hace con respecto a las dos categorías principales de derechos relacionada con la interconexión, interrelación e interdependencia que existe entre ellos, permitiría la estrategia de la defensa jurídico-procesal consistente en reclamar por las violaciones de los derechos sociales, a través de los mecanismos de los derechos civiles y políticos que tienen una mejor estructura, mucho más eficaz y con un mayor poder de coerción ${ }^{75}$.

\section{LOS DERECHOS SOCIALES COMO DERECHOS SUBJETIVOS DISCAPACITADOS}

Aunque los argumentos recién expuestos logran hacer frente a las objeciones que se formulan a la juridicidad y a la justiciabilidad de los derechos sociales, no consiguen el ob-

\footnotetext{
70 Hohfeld (1992) pp. 47-52.

71 Hohfeld (1992) p. 68.

72 Bastida (2007) pp. 116-119.

73 Abramovich y Courtis (2004) p. 38 (nota No 37 de ese trabajo).

74 Ruiz-Tagle (2009) p. 23.

75 Rossetti (2010) p. 121 (nota No 54).
} 
jetivo de equipararlos con los derechos liberales, porque no se puede dejar de admitir que a los primeros les falta algo relevante con lo que sí cuentan los segundos.

Por mucho que se insista en la justiciabilidad de los derechos sociales alegando que la indeterminación que se les atribuye afecta del mismo modo a los derechos liberales, la realidad se impone por sobre cualquier argumento. Así, aunque fueren susceptibles de tutela judicial, lo que de hecho ocurre es que, por regla general, no se prevé un recurso que efectivamente garantice la posibilidad de entablar un reclamo judicial para el caso que se incumplan la obligaciones que estos derechos reflejan ${ }^{76}$. Como esto es, para algunos, una razón suficiente para negarles juridicidad, se argumenta que es un error afirmar que la existencia de un derecho depende de su garantía judicial.

Se debe notar que la importancia de mantener diferenciados a los derechos de su garantía judicial, que en principio es la base del argumento para la equiparación, tiende a relativizarse cuando, para defender la juridicidad de los derechos sociales, se insiste en la existencia de otras potenciales formas de exigibilidad, algunas de ellas de indiscutible carácter judicial. Dicho de otro modo, a este tipo de defensa podría objetarse que es llevada a cabo al precio de reconocer que los derechos subjetivos deberían ser, a fin de cuentas, algo más que el mero reflejo de obligaciones.

Como observa Cruz Parcero, conscientes de que buena parte del escepticismo sobre los derechos sociales se basa en constatar que su protección y cumplimiento han sido problemáticos y muy deficientes, los defensores de los derechos sociales se han preocupado por encontrar fórmulas para brindarles protección y garantizarlos jurídicamente. En este contexto, lo ideal para algunos de estos autores sería encontrar el modo de hacerlos justiciables, es decir, que al igual que otros derechos, sea posible demandar la intervención judicial para su debida protección ${ }^{77}$.

En el foco de esta crítica se encuentran, sin ninguna duda, quienes consideran que para afirmar la exigibilidad de estos derechos es suficiente el reconocimiento jurídico de "algún” poder de reclamo, aunque este no exista en todos los casos de violaciones ${ }^{78}$, y asimismo quienes afirman la posibilidad de reclamar los derechos sociales bajo formas convertidas de derechos liberales que sí cuentan con recursos que los garantizan ${ }^{79}$, o a partir de la eficacia directa de la norma iusfundamental ${ }^{80}$, o al amparo de los instrumentos internacionales que obligan a los Estados a proveer de recursos judiciales efectivos frente a posibles violaciones de los derechos fundamentales.

$\mathrm{Al}$ margen de si estos argumentos adolecen de esta cuota de inconsistencia, lo relevante es advertir que las formas de exigibilidad que se proponen para los derechos sociales

\footnotetext{
76 En el contexto chileno se trata de un hecho insoslayable; VV.AA. (Ruiz-Tagle (2009) p. 23; Peña (2010) pp. 302-303; HeRnÁNDEZ (2010) pp. 320-323; SiLva (2012) p. 43).

77 CRUZ (2007) p. 71.

78 Aвramovich y Courtis (2004) p. 38 (nota No 37).

79 Rossetti (2010) p. 121 (nota No 54). El problema es a tal punto insoslayable que, aunque se reconozca que la transformación de los derechos que son sociales en libertades y la derivación de su garantía judicial en la convertibilidad constitucional se han debido a la influencia neoliberal, se intenta rescatar los beneficios de esta estrategia invistiéndola con las credenciales de la perspectiva democrática y liberal; RuIz-TAGLE (2009) pp. 23-24.

80 Bastida (2007) pp. 116-119.
} 
no logran la pretendida equiparación de estos con los derechos liberales, por mucho que se insista en son derechos subjetivos en sentido jurídico y derechos "verdaderos".

La circunstancia de que la exigibilidad judicial de estos derechos pueda materializarse bajo formas convertidas de derechos liberales, el hecho que su demanda judicial pueda fundarse en los instrumentos internacionales que obligan a los Estados a proveer recursos judiciales efectivos para proteger los derechos, o que los derechos sociales sean exigibles frente a algunos casos de violación, no cambia su posición desaventajada frente a los derechos liberales que, en cambio, habitualmente cuentan un recurso especialmente destinado a su protección judicial. Por el contrario, los intentos de buscar fórmulas para hacer a los derechos sociales judicialmente exigibles pone precisamente en evidencia su insoslayable diferencia con los derechos liberales.

Es importante que se note que, tanto para los detractores como para los defensores de los derechos sociales, el concepto de derecho reflejo juega un papel fundamental. Recuérdese que, desde el primero de estos puntos de vista, los derechos subjetivos son también derechos reflejos, aunque provistos de un poder jurídico para reclamar frente al incumplimiento de la obligación. De otra forma, carecería de fundamento la consideración de los derechos sociales a los que falta la garantía judicial como derechos subjetivos "sobre el papel”. Desde el segundo punto de vista, los derechos subjetivos son precisamente el reflejo de obligaciones jurídicas, al margen de que sean exigibles y de la forma que adopte su exigibilidad. Es justamente la presencia de una obligación jurídica, es decir, la existencia de un derecho reflejo, lo que permite que los derechos sociales sean vistos como derechos subjetivos, mientras la ausencia de garantía opera como una razón para reconocer la precariedad de su situación.

En este sentido, la distancia efectivamente se reduce, pero la distinción se mantiene. Aunque los derechos sociales hayan sido reconocidos por las constituciones modernas y los tratados internacionales y, pese a que hoy sea posible observar que ellos están siendo tomados en cuenta bajo diversas formas por la jurisprudencia, su situación de violación permanente es una realidad cotidiana en la que se encuentran millones de personas ${ }^{81}$, frente a lo cual la justicia parece estar, por regla general, atada de manos.

Desde allí, la positivización, tanto constitucional como internacional de los derechos sociales, admite ser interpretada como una mera apariencia de solución legítima y justa y, por tanto, como una forma de camuflar y enmascarar el problema de la falta de reconocimiento, protección y garantía de estos derechos humanos imprescindibles para desarrollar una vida digna en libertad ${ }^{82}$. Frente a la vigencia formal e incluso a la extensión de los derechos sociales en muchas constituciones y tratados internacionales, la práctica impone su progresivo vaciamiento normativo a manos de una nueva lex mercatoria, cada vez más global, que debilita de manera sensible su eficacia vinculante y, con ello, el alcance mismo del principio democrático y el Estado de derecho ${ }^{83}$.

\footnotetext{
81 Rossetti (2010) p. 102.

82 Martínez Roldán (2009) pp. 114 y 138-142.

83 Pisarello (2007) p. 13.
} 
Los derechos sociales aparecen como derechos incompletos, deficientes, discapacitados o devaluados, frente a los generalmente impecables derechos civiles y políticos.

\section{CONCLUSIONES}

Cualquiera sea el mérito de los argumentos que se formulan tanto a favor como en contra de la equiparación de los derechos sociales con los liberales, lo concreto es que la disputa no ha terminado y que la situación de los primeros, en lo fundamental, no ha variado.

Tanto es así que, aunque a estas alturas la tendencia predominante sea la de admitir su juridicidad, el sostenido esfuerzo argumentativo dirigido a diluir sus diferencias con los derechos liberales, incluida la estrategia de convertirlos en estos para hacerlos judicialmente exigibles contribuye, antes que a una efectiva mejora de su situación, a poner de manifiesto la precariedad de la misma. Los derechos sociales aparecen como derechos incompletos, deficientes, discapacitados o devaluados frente al estatuto privilegiado de los derechos civiles y políticos.

Mi sugerencia es entonces que la situación devaluada en la que efectivamente se encuentran las exigencias de justicia que suelen agruparse bajo la denominación de derechos sociales no puede calibrarse mediante su comparación con los derechos liberales, civiles y políticos ni puede salvarse procurando su equiparación; y que la razón de ello no debe buscarse en los derechos sociales sino en los liberales, particularmente en la forma en que estos han sido generalmente entendidos.

El foco debe ser puesto entonces en los denominados derechos liberales. Específicamente, se debe revisar su general aceptación como derechos subjetivos que reflejan obligaciones estatales, aceptación que suele ser compartida, tanto por quienes defienden su diferenciación con los derechos sociales, como por quienes la rechazan. Este cambio en la perspectiva de análisis se justifica, cuando menos, porque la reconstrucción de los llamados derechos liberales (civiles y políticos) como derechos subjetivos que reflejan obligaciones estatales de abstención, exige que, al menos, sea puesto entre paréntesis el rol que corresponde a los llamados derechos políticos en la formación de la voluntad estatal ${ }^{84}$. Y esto demuestra que la señalada reconstrucción es incapaz de fundamentar que los derechos civiles y los derechos políticos sean agrupados bajo una misma categoría analítica.

\section{BIBLIOGRAFÍA CITADA}

Abramovich, Víctor y Courtis, Cristian (2004): Los derechos sociales como derechos exigibles (Madrid, Trotta).

AleXY, Robert (2007): Teoría de los derechos fundamentales (Madrid, Centro de Estudios Políticos y Constitucionales, segunda edición, trad. Carlos Bernal Pulido).

\footnotetext{
${ }^{84}$ Ver nota No 4 de este trabajo. Digo "cuando menos" porque la muy frecuente pretensión de que los llamados derechos civiles y los llamados políticos son subsumibles bajo una sola y misma categoría no solo es atacable por su déficit explicativo sino también por ser derechamente problemática. Sobre este punto, VV. AA. (BERLIN (2004) pp. 216 y 249; RuIz (2002) pp. 269 y 281-282; BAYÓN (2004) pp. 73 y ss.; AleXY (2007) pp. 395-396).
} 
Alexy, Robert (2009): "Los derechos fundamentales en el Estado Constitucional Democrático", en Carbonell, Miguel (edit.), Neoconstitucionalismo(s) (Madrid, Trotta, cuarta edición, trad. Alfonso García Figueroa) pp. 31-47.

Aldunate, Eduardo (2008): Derechos fundamentales (Santiago, LegalPublishing).

Ansuátegui, Francisco (2010): “Argumentos para una teoría de los derechos sociales”, en Ribotta, Silvina y Rossetti, Andrés (edit.), Los derechos sociales en el siglo XXI. Un desafio clave para el derecho y la justicia (Madrid, Dykinson).

ArAngo, Rodolfo (2005): El concepto de derechos sociales fundamentales (Bogotá, Legis, Universidad Nacional de Colombia).

Arriagada, María Beatriz (2010): "La discrecionalidad del destinatario de la norma en el cumplimiento de lo prescrito como criterio de distinción estructural en el contexto del sistema primario", Anuario de Filosofía Jurídica y Social, No 28: pp. 11-83.

Arriagada, María Beatriz (2012): "Los derechos sociales: Únicos derechos fundamentales", en Aguilar, Gonzalo (coord.), Derechos económicos, sociales y culturales en el orden constitucional chileno (Santiago, Librotecnia).

Atienza, Manuel y Ruiz Manero, Juan (2004): Las piezas del derecho (Barcelona, Ariel, cuarta edición).

BAYÓN, Juan Carlos (2004): Constitución y derechos fundamentales (Madrid, Centro de Estudios Políticos y Constitucionales).

Barranco, M. Carmen (2010): "Exigibilidad de los derechos sociales y democracia”, en RIвоттA, Silvina y Rossetti, Andrés (edit.), Los derechos sociales en el siglo XXI. Un desafío clave para el derecho y la justicia (Madrid, Dykinson) pp. 149-171.

BAstidA, Francisco (2007): “¿Son los derechos sociales derechos fundamentales? Por una concepción normativa de la fundamentalidad de los derechos", en AlEXY, Robert et al., Derechos sociales y ponderación (Madrid, Fundación Coloquio Jurídico Europeo) pp. 103-149.

Berlin, Isaiah (2004): “Dos conceptos de libertad”, en Sobre la libertad (Madrid, Alianza, trad. Julio Bayón, Ángel Rivero, Natalia Rodríguez y Belén Urrutia) pp. 205-255.

Bernal, Carlos (2004): "Fundamento concepto y estructura de los derechos sociales. Una crítica a "¿Existen los derechos sociales?" de Fernando Atria”, Doxa, Discusiones: Derechos sociales, No4: pp. 99-144.

BobBio, Norberto (2009): Teoría general de la politica (Madrid, Trotta, tercera edición, trad. Antonio de Cabo y Gerardo Pisarello).

Calvo, Manuel (2009): "La implementación y efectividad de los derechos económicos sociales y culturales”, en Zapatero, Virgilio y Garrido, María Isabel (edit.), Los derechos sociales como una exigencia de la justicia (Madrid, Cuadernos democracia y derechos humanos, Universidad de Alcalá) pp. 201-225.

Carbonell, Miguel (2008): "Eficacia de la Constitución y derechos sociales: esbozo de algunos problemas", Revista de Derecho Público Universidad de Chile, vol. 70, pp. 23-47.

Cruz Parcero, Juan Antonio (2004): "Leones, lenguaje y derechos. Sobre la existencia de los derechos sociales (Réplica a Fernando Atria)", Doxa, Discusiones: Derechos sociales, No 4: pp. 71-98. 
Cruz Parcero, Juan Antonio (2007): El lenguaje de los derechos. Ensayo para una teoría estructural de los derechos (Madrid, Trotta).

Diciotтi, Enrico (2004): "Sulla distinzione tra diritti di libertà e diritti sociali: una prospettiva di filosofía analitica”, Quaderni costituzionalil a. XXIV, No 4: pp. 733-762.

EIdE, A. (2001): "Economic, Social and Cultural Rights as Human Rights", en EIDE, Absjorn (edit.), Economic, Social and Cultural Rights (Dordrecht, Martinus Nijhof Publishers).

Ferrajoli, Luigi (2002): "Juspositivismo crítico y democracia constitucional”, Isonomía. Revista de Teoría y Filosofía del Derecho, No 16, abril: pp. 7-20.

Ferrajoli, Luigi (2009): Derechos y garantías. La ley del más débil (Madrid, Trotta, sexta edición, trad. Perfecto Andrés Ibáñez y Andrea Greppi).

FigueroA, Rodolfo (2009a): "Justificación del rol de las cortes haciendo justiciables los derechos económicos, sociales y culturales, en particular el derecho a la protección de la salud", Revista Chilena de Derecho, vol. 36, No 2: pp. 313-342.

Figueroa, Rodolfo (2009b): "Justiciabilidad de los derechos económicos, sociales y culturales. Discusión teórica”, Revista Chilena de Derecho, vol. 36 No 3: pp. 587-620.

Fioravanti, Maurizio (2007): Los derechos fundamentales. Apuntes de historia de las constituciones (Madrid, Trotta, quinta edición, trad. Manuel Martínez Neira).

Guastini, Riccardo (1999): Distinguiendo. Estudios de teoría y metateoría del derecho (Barcelona, Gedisa, primera edición, trad. Jordi Ferrer).

GuASTINI, Riccardo (2010): Interpretación, Estado y Constitución (Lima, Ara, primera edición).

Habermas, Jurgen (2008): Teoría y praxis. Estudios de filosofía social (Madrid, Tecnos, quinta edición, trad. Salvador Mas Torres y Carlos Moya Espí).

Hart, H.L.A. (1983): "Legal Rights", en Essays on Bentham. Studies in Jurisprudence and Political Theory (New York, Oxford University Press) pp. 162-193.

Hernández, Domingo (2010): "Derechos económicos sociales y culturales en la jurisprudencia de los tribunales superiores de justicia”, en Nogueira, Humberto (coord.), Dogmática y aplicación de los derechos sociales (Santiago, Librotecnia) pp. 319-340.

Hesse, Conrado (2001): "Significado de los derechos fundamentales", en Benda et al., Manual de Derecho Constitucional (Madrid, Evap-Marcial Pons, segunda edición, trad. Antonio López Pina) pp. 1-15.

Hierro, Liborio (2000): “QQué derechos tenemos?, Doxa, No 23: pp. 351-375.

Hierro, Liborio (2007): "Los derechos económico-sociales en la teoría de los derechos de Robert Alexy," en Alexy, Robert et al., Derechos sociales y ponderación (Madrid, Fundación Coloquio Jurídico Europeo) pp. 163-222.

Hohfeld, Wensley (1992): Conceptos jurídicos fundamentales (México D.F., Fontamara, segunda edición, trad. Genaro Carrió).

Holmes, Stephen y Sunstein, Cass (2011): El costo de los derechos. Por qué la libertad depende de los impuestos (Buenos Aires, Siglo XXI, trad. Stella Mastrangelo).

Kelsen, Hans (1987): Problemas capitales de la teoría jurídica (México D.F., Porrúa, trad. Wenceslao Roces).

Kelsen, Hans (1991): Teoría pura del Derecho (México D.F., Porrúa, decimosexta edición, trad. Roberto J. Vernengo).

LAPORTA, Francisco (1987): "Sobre el concepto de derechos humanos", Doxa, No 4: pp. 23-46. 
Lema, Carlos (2010): "La disputada universalidad de los derechos sociales. Entre asistencialismo y desmercantilización”, en Riвотta, Silvina y Rossetтi, Andrés (edit), Los derechos sociales en el siglo XXI. Un desafío clave para el derecho y la justicia (Madrid, Dykinson) pp. 77-100.

Marshall, T.H. (1998): Ciudadanía y clase social (Madrid, Alianza, trad. Pepa Linares).

Martínez de Pisón, José (2009): "Los derechos sociales: unos derechos controvertidos," en Zapatero, Virgilio y Garrido, María Isabel (edit.), Los derechos sociales como una exigencia de la justicia (Madrid, Cuadernos democracia y derechos humanos, Universidad de Alcalá) pp. 89-111.

Martínez Roldán, L. (2009): "Los derechos sociales como derechos humanos y como derechos constitucionales”, en Zapatero, Virgilio y Garrido, María Isabel (edit.), Los derechos sociales como una exigencia de la justicia (Madrid, Cuadernos democracia y derechos humanos, Universidad de Alcalá) pp. 113-142.

Moreso, José Juan (2009): “Esbozo de preliminares a una teoría de la constitución”, en La Constitución: modelo para armar (Madrid, Marcial Pons) pp. 21-66.

Nogueira, Humberto (2010): "Los derechos económicos, sociales y culturales como derechos fundamentales efectivos en el constitucionalismo democrático latino americano", en Nogueira, Humberto (coord.), Dogmática y aplicación de los derechos sociales (Santiago, Librotecnia) pp. 9-93.

NúNEEZ, J. Ignacio (2012): "Estado constitucional de derecho y ponderación: Hacia la superación de la falsa disyuntiva entre libertad y satisfacción de los derechos sociales fundamentales", en Aguilar, Gonzalo (coord.), Derechos económicos, sociales y culturales en el orden constitucional chileno (Santiago, Librotecnia) pp. 113-124.

Peces-Barba, Gregorio (1999a): Curso de derechos fundamentales Teoría General (Madrid, Universidad Carlos III de Madrid, Boletín Oficial del Estado).

Peces-Barba, Gregorio (1999b): Derechos sociales y positivismo jurídico (Madrid, Dykinson) pp. 7-66.

PeÑA, Marisol (2010): “Aplicación de los derechos económicos, sociales y culturales por el Tribunal Constitucional chileno", en Nogueira, Humberto (coord.), Dogmática y aplicación de los derechos sociales (Santiago, Librotecnia) pp. 299-318.

Prieto Sanchís, Luis (1998): Ley, principios, derechos (Madrid, Dykinson).

Prieto Sanchís, Luis (2000): "La limitación de los derechos fundamentales y la norma de clausura en el sistema de libertades", Derechos y libertades, No 8: pp. 429-468.

Pérez Luño, Antonio (1984): Los derechos fundamentales (Madrid, Tecnos, décima edición).

Pisarello, Gerardo (2007): Los derechos sociales y sus garantías. Elementos para una reconstrucción (Madrid, Trotta).

Rossetti, Andrés (2010): “Algunos mitos, realidades y problemas en torno a los derechos sociales”, en Riвотta, Silvina y Rossetтi, Andrés (edit.), Los derechos sociales en el siglo XXI. Un desafio clave para el derecho y la justicia (Madrid, Dykinson) pp. 101-126.

Ruiz-Tagle, Pablo (2009): "Un proyecto constitucional para la generación del bicentenario: Igualdad y derechos sociales y económicos en Chile", Revista de Derecho y Humanidades, No 15: pp. 17-35. 
Ruiz Miguel, Alfonso (1994): "Derechos liberales y derechos sociales”, Doxa, No 15-16: pp. 651-674.

Ruiz Miguel, Alfonso (2002): Una filosofía del derecho en modelos históricos. De la antigüedad a los inicios del constitucionalismo (Madrid, Editorial Trotta, segunda edición).

Silva, María Pía (2012): "El Estado social de derecho en la Constitución chilena”, en AgUILAR, Gonzalo (coord.), Derechos económicos, sociales y culturales en el orden constitucional chileno (Santiago, Librotecnia) pp. 29-48.

Tugendhat, Ernst (1998): Ser-Verdad-Acción. Ensayos filosóficos (Barcelona, Gedisa, trad. Rosa Helena Santos Ilhau).

Waldron, Jeremy (2005): Derecho y desacuerdos (Madrid, Marcial Pons, trad. José Luis Martí y Águeda Quiroga).

ZúNiga, Alejandra (2012): "Las teorías de la justicia de nuestra Constitución", en Aguilar, Gonzalo (coord.), Derechos económicos, sociales y culturales en el orden constitucional chileno (Santiago, Librotecnia) pp. 49-60. 